\title{
Mitral Valvotomy in Patients Aged 50 Years and Over
}

\author{
J. M. REID,* M.D., M.R.C.P.ED. ; R. S. BARCLAY,† M.D., F.R.C.S.ED., F.R.C.S.GLASG. \\ J. G. STEVENSON,* M.D., M.R.C.P.GLASG. ; T. M. WELSH,† M.B., F.R.C.S.ED., F.R.C.S.GLASG. \\ N. MCSWAN, $\dagger$ M.B., F.R.C.S.GLASG.
}

Brit. med. F., 1966, 2, 1044-1046

Mitral valvotomy is a well-established procedure and is indicated in patients who have symptoms due to rheumatic mitral stenosis. The risk of operation in the younger age group (up to 50 years of age) is now very low, but in older patients it is a more formidable undertaking with greater risks owing to associated degenerative heart and cerebrovascular disease. Furthermore, there is considerable controversy on how much benefit will accrue from mitral valvotomy in this age group. It was for these reasons that a retrospective study was carried out of all patients aged 50 and over who had mitral valvotomy performed in the cardiothoracic unit at Mearnskirk Hospital.

\section{Material}

The period under review extends from early 1953 up to the latter part of 1965 , during which time mitral valvotomy was performed in 704 patients, 99 of whom were aged 50 and over. These 99 patients form the basis of the present communication. The number in each age group is shown in Table I.

\begin{tabular}{|c|c|c|c|c|c|}
\hline $\begin{array}{l}\text { Age group } \\
\text { No. of patients } . .\end{array}$ & $\ddot{x}$ & $\underset{57}{50-53}$ & $\begin{array}{c}54-57 \\
29\end{array}$ & $\begin{array}{c}58-61 \\
10\end{array}$ & $\frac{62-65}{3}$ \\
\hline
\end{tabular}

There was the usual sex preponderance, 77 of the patients being female. The incidence of atrial fibrillation was strikingly high (71), but that is hardly surprising in this age group. Olesen (1962), in a study of 271 patients with mitral stenosis who had not been operated on, found atrial fibrillation in $55 \%$, the average age in his series being 41.5 years. A previous history of rheumatic fever was obtained in 45 of the present 99 , some of the patients having experienced two or more attacks. Substantial exertional dyspnoea was present in all, varying in most from grade II to grade III, but with a small number in grade IV. In some of our patients the existence of a heart condition had been known for many years before the onset of troublesome symptoms. One patient aged 55, although aware that she had had mitral stenosis since the age of 30 , had become incapacitated only in the last few years.

Pulmonary arterial hypertension was present in a significant degree in 77 , in 10 of whom the systolic pressure ranged from 70 to $100 \mathrm{~mm}$. $\mathrm{Hg}$.

\section{Associated Conditions}

Many patients with mitral-valve disease are prone to recurrent attacks of bronchitis, and one would expect to encounter this more often in older patients. Fifteen of our patients could be classified as suffering from chronic bronchitis, and this proved an additional hazard in the immediate post-operative phase.

- Consultant Physician, Cardiothoracic Unit, Mearnskirk Hospital, Newton Mearns, Glasgow.

† Consultant Thoracic Surgeon, Cardiothoracic Unit, Mearnskirk Hospital, Newton Mearns, Glasgow.
Systemic hypertension was recorded in 14 pre-operatively, and evidence of renal damage (albuminuria with raised blood urea and creatinine) was noted in five of those. Repeated emboli lodging in the kidney are now known to be a potent cause of subsequent renal damage and hypertension in mitral-valve disease (Obeyesekere et al., 1965), and it is reasonable to assume that such was the case in these five. A further two patients, who pre-operatively had normal blood pressure and renal function, have since developed this syndrome, several years after valvotomy.

Rather surprisingly, in only two patients was there unequivocal evidence from both the history and the electrocardiogram of previous coronary infarction, although several others had angina which improved after successful valvotomy.

Pre-operative embolism occurred in 14 instances, the commonest site being cerebral (5), followed by femoral artery (3), saddle (2), pulmonary (2), and one each involving the popliteal and radial arteries.

\section{Operative Data}

In 88 of the 99 patients valvotomy was undertaken as a primary procedure, and 11 were repeat operations. A fingersplit was performed in four, but in the remainder an instrumental dilatation through the ventricle was achieved with the instrument preset at $3.5-4 \mathrm{~cm}$. Most had a satisfactory split of the anterior commissure, a smaller number the posterior one, and in several cases both commissures were split. Significant calcification was observed in 22 valves, but although this did not necessarily prejudice a satisfactory valvotomy there was a greater tendency to produce incompetence in this group. Bailey (1955) observed calcification of the mitral valve at operation in $39 \%$ of his patients, and Michell (1960) recorded an incidence of $32 \%$. Dubost et al. (1962) noted calcification in $176(17 \%)$ of 1,000 cases. Clot was encountered in the left atrium in 12 instances, and was evacuated without subsequent incident.

Some degree of incompetence was produced in 41 cases, but in most this was only minimal. In only three patients was the regurgitation severe, and two of these died in the post-operative phase from intractable congestive cardiac failure. The third patient is still alive seven years after operation, but has gross mitral incompetence with considerable incapacity. Her age and the presence of systemic hypertension associated with chronic renal disease preclude mitral-valve replacement with a Starr-Edwards prosthesis. Otto (1964), reviewing 565 operations for mitral stenosis, found incompetence post-operatively in $171(30.7 \%)$.

Operative Mortality.-This embraces all deaths occurring within six weeks of operation, and Table II lists the causes in the 14 who died. Gross mitral incompetence produced at operation in valves which were heavily calcified contributed in large measure to the two deaths from cardiac failure. Those attributable to cardio-respiratory failure were precipitated by an acute purulent bronchitis in the early post-operative period, and three of these had been subiect to recurrent bronchitis. Myocardial infarction accounted for a fatal outcome in three patients, 
all occurring within 12 to 72 hours of operation. The patient who died from haemorrhage was having a repeat valvotomy. The ventricular wall was extremely friable at the site of introduction of the Tubbs dilator, and despite repeated attempts to control the haemorrhage the patient died in the theatre.

Table II.-Causes of Death Post-operatively in 14 Patients

\begin{tabular}{c|c|c|c|c|c|c}
\hline $\begin{array}{c}\text { Cardio- } \\
\text { respiratory } \\
\text { Failure }\end{array}$ & $\begin{array}{c}\text { Myo- } \\
\text { cardial } \\
\text { Infarction }\end{array}$ & $\begin{array}{c}\text { Congestive } \\
\text { Cardiac } \\
\text { Failure }\end{array}$ & $\begin{array}{c}\text { Cerebral } \\
\text { Embolism }\end{array}$ & $\begin{array}{c}\text { Pulmonary } \\
\text { Embolism }\end{array}$ & $\begin{array}{c}\text { Renal } \\
\text { Failure }\end{array}$ & $\begin{array}{c}\text { Haemorrhage } \\
\text { from Left } \\
\text { Ventricle }\end{array}$ \\
\hline 4 & 3 & 2 & 2 & 1 & 1 & 1 \\
\hline
\end{tabular}

\section{Post-operative Complications}

Atrial Fibrillation.-Of 28 patients who were in sinus rhythm prior to operation, 11 developed rapid atrial fibrillation early in the post-operative period. All were successfully defibrillated by means of digoxin alone, digoxin initially followed by quinidine, or by cardioversion. An additional patient whose atrial fibrillation was of short duration pre-operatively was defibrillated by the cardioverter, but in the 70 with atrial fibrillation before valvotomy it was thought unwise to attempt reversion.

Pulmonary Embolism.-This occurred in two patients, one of whom already referred to died; the other made a good recovery.

Systemic Embolism.-Cerebral embolism was responsible for death in two patients, but a third patient in whom this was encountered made a good recovery. One patient required removal of a saddle embolus one week post-operatively, but again there was a successful outcome.

Overall, the incidence of embolic complications in this age group has been extremely low (four) in our experience, and this we attribute to the routine employment of anticoagulant therapy from the third post-operative day in all patients who either had fibrillation or were aged 40 and over. The incidence quoted in the literature (Sellors et al., 1953 ; Bailey, 1955) has varied between $4 \%$ and $7 \%$.

Renal Failure.-This has already been alluded to, and proproduced a fatal termination in one patient.

Cardio-respiratory Insufficiency.-Six patients developed signs of this condition. All were treated with oxygen therapy, antibiotics, and tracheostomy, and in addition three required controlled respiration on a ventilator. Despite these measures four of the six died.

\section{Results of Operation}

All of the 85 who survived operation have been followed up for periods ranging from six to nine years. During this time 11 have died-eight from congestive cardiac failure, one due to congestive cardiac failure and subacute bacterial endocarditis, one from subacute bacterial endocarditis with gangrene of both legs, and one from a cause unknown. Four of the 11 died within a year of operation, the remainder one to six years later. Valve-calcification was present in four of the 11 at operation, and pulmonary hypertension was recorded in eight. Significant mitral incompetence was present in six either before or after valvotomy.

Thus 74 are still alive. Table III shows the period of followup since operation.

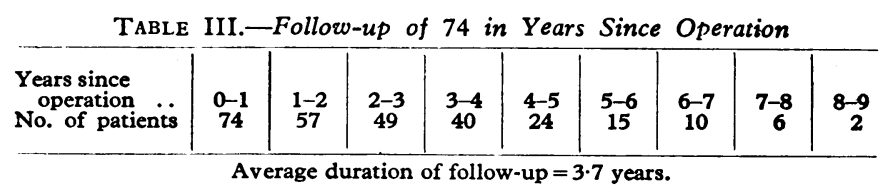

Four of these 74 patients have shown no subjective or objective improvement. A further 12 derived considerable benefit from operation initially for a variable period of three to five years, but have since deteriorated and are now in a state of congestive cardiac failure with frank mitral incompetence. Three of these have systemic hypertension with renal damage, due in all probability to recurrent renal emboli (Obeyesekere et al., 1965). Fifty-eight, however, have maintained their improvement since operation, the period of follow-up being six months to nine years. Admittedly many of them are on digoxin therapy to control atrial fibrillation, and a proportion require the frequent administration of diuretics, but all are active and able to cope with their household duties.

\section{Discussion}

In a review of any large series of patients suffering from mitral stenosis it is pertinent to review the results of any form of treatment in the light of the natural history of the disease. Wood (1956) stated that the average age at onset of symptoms in his series of mitral stenosis was 31 years, and the mean age of death was 40 years. Many of our patients were symptomfree until they reached the forties, and others whose disability had developed earlier had only trivial symptoms until a comparatively late stage of the disease. Olesen (1962) followed up 271 patients who were not treated surgically, the average mean age when first seen being 41.5 years. All had moderate-tosevere symptoms, $55 \%$ being in atrial fibrillation. Within 11 years from the first observation $70 \%$ were dead, and an additional $18 \%$ had shown further deterioration. Furthermore, he found that the patients over 50 years of age fared worse than the younger ones.

In their series of 500 patients who underwent mitral valvotomy (Lowther and Turner, 1962) 57 were aged 50 or over, the mortality being $18 \%$ in this age group. Our mortality (14\%) may also seem formidable compared with an overall operative death rate of $6 \%$ for our entire series of mitral valvotomy (a total of 704). This figure, however, is quite acceptable when viewed against the short life expectancy in those not surgically treated. Furthermore, these elderly patients have in many instances accompanying disorders, such as systemic hypertension, coronary and cerebral vascular disease, and chronic lung disease, which adversely influence the outcome.

That atrial fibrillation was present in 71 pre-operatively is not surprising in this age group. The high incidence of emboli (14 prior to operation) is in itself a cogent indication for surgery to prevent further episodes. Systemic hypertension was noted in 14, but this need not preclude surgical intervention and a satisfactory result. What was of rather ominous portent was the presence of chronic bronchitis and emphysema. Of 15 patients in this category four died early in the post-operative period from cardio-respiratory failure. Manifestly such patients require very careful and close supervision by both medical and nursing attendants, and tracheostomy with controlled ventilation should be undertaken at the earliest sign of cardiorespiratory embarrassment.

Valve calcification was encountered in 22 patients, and this feature must be regarded adversely (Goodwin et al., 1955 ; Mounsey, 1957). Two died post-operatively-one with a cerebral embolus probably due to a plaque of calcium-and mitral incompetence was produced in 12. Restenosis may result from an inadequate valvotomy or from further progression of the rheumatic process (Fraser and Kerr, 1962; Logan et al., 1962 ; Belcher and Gupta, 1964), and repeat valvotomy must invariably carry a greater risk. Eleven of our 99 patients had second operations ; three of them died postoperatively and a fourth nine months later.

The natural question which arises is: Is mitral valvotomy justifiable in patients over the age of 50 ? Accepting that the mortality is higher, owing to accompanying degenerative heart and cerebrovascular disease, our results would support the contention that operation is certainly both worth while and rewarding in this age group. That chronic lung disease and renal 
damage are more common and may adversely affect the result is indisputable, but without surgery the outlook is indeed grave. After mitral valvotomy most patients can look forward to many years of improved well-being and increased exercise tolerance.

\section{Summary and Conclusions}

The results are reported of 99 patients aged 50 and over who underwent mitral valvotomy. The immediate mortality was $14(14 \%)$, and a further 11 have died during the period of follow-up, which has varied from six months to nine years. Most of the survivors have benefited from operation and have maintained their improvement even when slight mitral incompetence has been produced. Chronic bronchitis with emphysema, severe pulmonary arterial hypertension, and valve calcification are more common in this age group, and increase both the mortality and the morbidity. Careful supervision is important in the immediate post-operative period.
We wish to thank the many physicians in the region who referred patients for operation.

REFERENCES

Bailey, C. P. (1955). Surgery of the Heart, pp. 544, 639. Kimpton, Belcher, J. R., and Gupta, R. L. (1964). Brit. med. 7., 1, 871.

Dubost, C., Blondeau, Ph., and Piwnica, A. (1962). F. thorac. cardiovasc. Surg., 44, 392.

Fraser, K., and Kerr, I. F. (1962). Brit. med. 7., 2, 443.

Goodwin, J. F., Hunter, J. D., Cleland, W. P., Davies, L. G., and Steiner, R. E. (1955). ibid., 2, 573.

Logan, A., Lowther, C. P., and Turner, R. W. D. (1962). Lancet, 1, 443.

Lowther, C. P., and Turncr, R. W. D. (1962). Brit. med. F., 1, 1027. Michell, G. (1960). Ibid, 1, 687 .

Mounsey, P. (1957). Ibid., 2, 311.

Obeyesekere, H. I., Dulake, M., Demerdash, H., and Hollister, R. (1965). Ibid., 2, 441 .

Olesen, K. H. (1962). Brit. Heart 7., 24, 349.

Otto, T. J. (1964). Thorax, 19, 541.

Sellors, T. H., Bedford, D. E., and Somerville, W. (1953). Brit. med. Sellors, T. H., Bedford, D. E., and Somerville, W. (1953). Brit. med. Wood, P. 1059. and Spottiswoode, London.

\title{
Viability of Common Pathogens in Cold-curing Acrylic Resin used in Orthopaedic Surgery
}

\author{
A. G. TOWERS,** M.B., B.S., B.SC., M.C.PATH.
}

Brit. med. 7., 1966, 2, 1046-1047

Sokolowski et al. (1955) demonstrated that the acrylic resin monomethyl methacrylate exhibited bacteriostatic activity towards oral micro-organisms. Dutton (1959) drew attention to the ease with which the polymer powder and the powder and liquid dough mix could be contaminated.

Cold-curing acrylic resins with benzoyl peroxide as the catalyst are being used increasingly in orthopaedic surgery, where a tight fit is required between an implant and the bone (e.g., to hold the intramedullary stem of a femoral prosthesis or acetabular replacement). Should infection occur at such a site the result can be most unfortunate for the patient. It is often difficult to remove the resin because of the way it keys into the bone.

Two commonly used products-Surgical Simplex $P$ and Nu-life'-have been examined recently. Surgical Simplex P was available in sterile packs. The powder or polymer is in a double polyethylene pack sterilized by high-energy radiation; the monomer is in ampoules, sterilized by Seitz filtration under positive pressure.

Both components of Nu-life are supplied non-sterile; the powder in 6-oz. (170-g.) plastic bottles and the fluid monomer in 4-oz. (114-ml.) glass bottles. Both kinds of pack favour repeated use and are thus apt to become contaminated.

Oliver and Blaine (1948) stated that acrylic monomer was sterile, but they included a bacterial check on the fluid before use. Charnley (1960) stated that the fluid monomer is self-sterilizing, and that he sterilizes the powder by prolonged exposure to formalin. It is not easy to sterilize the monomer by Seitz filtration under vacuum owing to the ease with which the filter becomes blocked. Judet et al. (1954) stated that some of their patients had a slight serous discharge after the use of acrylic

- Department of Biomechanics and Surgical Materials, Institute of Orthopaedics (University of London), Royal National Orthopaedic Hospital, Stanmore, Middlesex

2 Surgical Simplex $P-$ Northill Plastics Limited, London. Nu-lifeCottrell and Company Limited, London. prostheses which had been sterilized by formalin. Such discharge had not been seen since the method of sterilization by formalization had been abandoned. This would suggest that there is a possible uptake of formalin by the resin, and that some other method of sterilization of the powder would be preferable.

Curing or hardening of the resin mix is an exothermic reaction. Peak temperatures in the bone of about $95^{\circ} \mathrm{C}$. may be reached, and it might be thought the temperature and pressure changes which occur with the shrinkage of the resin, coupled with the presence of free monomer, would cause selfsterilization of the preparation.

\section{Results}

The viability of some common pathogens after they had been in contact with these materials was investigated. Tests were made on the powder, monomer, and cured dough with coagulase-positive and coagulase-negative staphylococci, betahaemolytic streptococcus, Bacillus cereus (for spores), Escherichia coli, Proteus vulgaris, and Pseudomonas pyocyanea in 18-hour cultures as the test organisms. Subculture was made at regular intervals to determine what degree of bacterial inhibition could be shown.

The malleable dough was worked well with the fingers, which when "printed" on to blood agar plates gave growth of skin commensals both before and after kneading. Discs of the set resin were also incubated in broth, and $50 \%$ were shown to be contaminated by skin commensals.

Subcultures made from 18-hour broth cultures after intervals of shaking with monomer showed there was a marked variation in survival time for the different test organisms. The haemolytic streptococcus could not be recovered after one minute, the staphylococci varied between 12 and 20 minutes, while the spore-forming $B$. cereus proved the most resistant. Recovery 